\title{
Construir un discurso propio
}

Keywords: máster; veterinarios

Este otoño 2011 ha venido cargado de actividades y de novedades que vale la pena reseñar aquí.

En primer término, el Master en Derecho Animal y Sociedad, comenzó su andadura en Septiembre con un buen grupo de alumnos (abogados, veterinarios, filósofos, sociólogos, psicólogos, periodistas), que participan con dedicación y entusiasmo en las clases. Esta primera edición, que fue precedida el curso pasado (2010-2011) por el Postgrado en Animales, Derecho y Sociedad, está contando con el apoyo entusiasta de un cuadro internacional de Profesores, que, como puede verse en el elenco que publicamos en la web, son profesionales de primer orden que transmiten sus conocimientos con solidez y pasión [1]. No conozco a nadie que llegue a transmitir eficazmente algo -un mensaje, una lección, un discurso-, si no está convencido y apasionado por lo que transmite. Es una regla clara y sencilla: que se hable de lo que se sabe, con convencimiento y entusiasmo. Lo decía de forma sintética Eugenio d’Ors (padre de mi Maestro, D.Alvaro d'Ors): “hay que repetir con entusiasmo, esta es la misión del que enseña!”. La primera parte de la regla: que se hable de lo que se sabe, se resume en una palabra: “expertise”, o, con el término que se acuñó en Roma: auctoritas, es decir el saber socialmente reconocido. No basta con saber, hay que transmitir con entusiasmo y repetir con el mismo entusiasmo de la primera vez. Ése es uno de los valores de este Máster, gracias al cuadro de Profesores que en él participan, a su generosidad, entusiasmo y entrega y gracias a unos alumnos excelentes.

Cuando se inician unos estudios como éstos -que eran desconocidos en Europa hasta el momento-, el planteamiento fue aunar a los expertos en cada materia y construir un Programa interdisciplinar, pues la perspectiva de estudio -el estatuto jurídico y el bienestar animal- son una unidad tanto por el objeto, por la finalidad, como por la pretensión: mejor formación individual, mayor profesionalización de los conocimientos, contribuir a que cada alumno (un profesional en ramas distintas del saber) construya un discurso propio, que sepa transmitir como tal, en el ámbito en donde desempeña sus conocimientos en favor de los animales. Parece un plan ambicioso y lo es, no queremos sólo informar, sino formar profesionales independientes y comprometidos con el bienestar animal. Este es uno de los grandes retos que ha asumido la Unión Europea, a través de la DG SANCO, sustanciado en un slogan muy sencillo e incisivo: "Cada uno de nosotros es responsable" (=Everyone is responsible).

En el Master pretendemos que cada participante construya un discurso propio en la defensa y protección de los animales. Hace poco hablaba con una colega, experta en la docencia del inglés, y me decía: se aprende un idioma de forma contextualizada, es decir, hablando en inglés de aquello que te interesa. En nuestra versión del aprendizaje y de la transmisión de conocimientos, es lo que estamos haciendo con la modestia propia de quien sabe que nunca se termina de aprender, siempre se puede mejorar en transmitir lo que se ha aprendido. Una enseñanza dinámica y un aprendizaje contextualizado, dan como resultado que el alumno del Máster se encuentre cómodo utilizando, cada día que avanza, un discurso propio. No con la repetición de ideas ajenas, que duran poco en la memoria y no definen a un buen profesional, sino aprendiendo a hablar creando tus propias ideas y avanzando en tu formación, de acuerdo a un Programa y al dialogo con los Profesores del Master.

En segundo lugar, recién iniciadas las clases del Máster, el Grupo de Investigación ADS que dirijo, con el impulso y participación del MICINN (Proyecto I+D, DER 2010-21301) de la European Comisión DG SANCO y la asociación internacional Minding Animals, organizó los días 24 y 24 de Octubre el Congreso "Animals and the Law", con la pretensión de acercar dos mundos que hasta ahora se han 
mantenido separados: el Derecho y los Animales. Se trataba de ahondar en los problemas y demandas que la sociedad tiene hoy planteadas en relación a los animales y en analizar las respuestas que el mundo jurídico ha venido dando, para una efectiva mejora en el trato a los animales y, especialmente, en examinar las respuestas que a dichas exigencias sociales, cada vez más sensibles a los animales, se han formulado en los dos grandes sistemas jurídicos occidentales: el Common Law y el Civil Law.

La convocatoria del Congreso reunió a algunos de los grandes expertos mundiales en este campo, venidos de Europa, los Estados Unidos de América, Canadá, Australia. Como novedad en este tipo de citas -al menos en España-, se incluyó una sección denominada "New Voices”, destinada a facilitar que los más jóvenes presentaran sus trabajos ante investigadores experimentados, para recibir sugerencias y críticas; los equipos de trabajo, cuando lo son de verdad, tiene que abrir las puertas para que se incorporen nuevos talentos. Fue una iniciativa que dio un magnífico resultado y sirvió de estímulo para todos, tanto participantes como asistentes.

La relación de los trabajos presentados y el historial de los participantes puede verse en nuestra web [2] . Lo que quizá no resulta tan fácil de percibir es el ambiente de trabajo y de intercambio intelectual que se creó entre todos los asistentes. Las sesiones se celebraron en el Hotel Campus de la UAB, que es un recinto excelente para estos eventos, por los medios de que dispone y por el personal que atiende a los participantes. No hay que olvidar que el Hotel es, al mismo tiempo una Escuela Hotelera, y los alumnos en prácticas son muchas veces los que ayudan a atender los diferentes servicios. Verlos tan jóvenes y tan disponibles crea, de entrada, un ambiente muy relajado y simpático que se transmite a todos.

Hubo ratos de discusión animada tanto durante las sesiones de preguntas como en los pasillos. Recuerdo la tertulia que Steven Wise formó alrededor suyo, en el hall del Hotel, que cada vez reunía a mas gente, hasta que al final terminamos formando una rueda, con algunos incluso sentados en el suelo. También tengo que destacar un momento especialmente emocionante en la formulación de "Conclusiones", al final del Congreso. Le pedí al Prof. David Favre que fuera él quien se encargara de la sesión. Con sus palabras, medidas y experimentadas, galvanizó a la audiencia al recordar que lo importante de un Congreso son las resultados que se logran, en nuestro caso preguntarnos, desde nuestro puesto de trabajo, qué podemos hacer para que la situación de los animales mejore, que iniciativas y políticas publicas promover para consolidar el respeto por los animales

En tercer lugar, los días 1 y 2 de Diciembre, tuve el honor de coorganizar los trabajos de un Workshop promovido la European Commission DG SANCO [3], la Federación Internacional de Veterinarios (FVE), el Consejo de Colegios Veterinarios [4] y el Ministerio de Agricultura, dirigido a la formación de veterinarios clínicos de países del sur de Europa (España, Francia, Italia, Grecia, Chipre, Malta), bajo el titulo: "Improving Animal Welfare". El componente jurídico de estos Talleres de Formación -el primero le los cuales tuvo lugar en Budapest-, trató de poner de relieve que la legislación debe ser un fiel reflejo de los avances científicos en tema de bienestar animal, por ello veterinarios y juristas debemos trabajar en estrecha colaboración.

El Workshop atrajo a muchos participantes, que contaron con dos sesiones perfectamente organizadas por el equipo humano de la DG SANCO, representado por Oana Barbulete, Carine Crouquet y Adrian Brouwn y por la Directora Ejecutiva de la FVE, Nancy de Brijne, divididas en una sesión de conferencias, una parte practica -preparatoria de las visitas a las granjas según el protocolo elaborado por Welfare Quality [5]-, de cuyo equipo forma parte el Catedratico de Etologia de la UAB, Xavier Manteca y en un día de visita a la granjas (de vacas lecheras, de cerdos y de aves) y al Zoo de Barcelona.

Termina un año 2011 lleno de trabajo, con la ilusión puesta en seguir trabajando más y mejor por los Animales. 
[1] Profesores

[2] Programa.

[3] Enlaces externos Onetec, Animalwelfare.

[4] Enlace externo.

[5] Mas información en Enlace externo 